\title{
PROFIBRINOLYSIN, ANTIFIBRINOLYSIN, FIBRINOGEN AND URINE FIBRINOLYTIC FACTORS IN THE HUMAN SUBJECT ${ }^{1}$
}

\author{
By M. MASON GUEST \\ (From the Department of Physiology, Wayne University College of Medicine, Detroit, Michi- \\ gan, and the Carter Physiology Laboratory, University of Texas Medical Branch, \\ Galveston, Texas)
}

(Submitted for publication March 30, 1954; accepted July 22, 1954)

This report describes methods for the quantitative assay of human plasma profibrinolysin (plasminogen) and for the semi-quantitation of fibrinolytic factors in urine. The concentrations of plasma profibrinolysin, antifibrinolysin, fibrinogen and lytic factors in urine of patients with an active neoplasm and in pregnant women are compared with their concentrations in normal individuals.

Although several methods have been described for the separation of human profibrinolysin from other constituents of plasma (1-5), the method described here appears to have the advantages that: (a) It can be utilized for quantitation; (b) it can be performed on a relatively small aliquot of plasma; (c) it is not influenced by the antifibrinolysin titer of the plasma; (d) it is highly reproducible; and (e) it does not require complex procedures or reagents which are difficult to obtain.

The blood and urine of approximately $200 \mathrm{hu-}$ man subjects were analyzed. Significant mean increases in plasma profibrinolysin, antifibrinolysin, and fibrinogen were found during pregnancy and in patients with neoplastic disease when compared with normal subjects. The fibrinolytic activity of urine was slightly but not significantly higher in patients with neoplasms than in normal individuals.

\section{MATERIALS AND METHODS}

Reagents. Protamine sulfate powder (Salmine) 2 was dissolved in 0.9 per cent $\mathrm{NaCl}$ to a final concentration of 0.8 per cent.

Imidazole, employed to buffer the fibrin clots at $\mathrm{pH}$ 7.25 , was prepared by dissolving $1.72 \mathrm{~g}$. of the free base

\footnotetext{
1 This work was supported by a Cancer Control Grant from the United States Public Health Service.

2 Supplied through the kind cooperation of Dr. W. R. Kirtley of Eli Lilly and Co.
}

in $90 \mathrm{ml}$. of $0.1 \mathrm{M} \mathrm{HCl}$. The $\mathrm{pH}$ was adjusted to 7.25 with $\mathrm{HCl}$ or $\mathrm{NaOH}$, and the volume brought to 100 ml. with distilled, or demineralized, water.

Streptokinase (Varidase $)^{8}$ was used to activate the profibrinolysin to fibrinolysin. The streptokinase-streptodornase preparation was dissolved in 0.9 per cent $\mathrm{NaCl}$ solution to produce a streptokinase solution containing 15,000 units per $\mathrm{ml}$.

The fibrinogen used for preparation of the fibrin substrate was obtained from bovine plasma by the freezethawing method (6). A 1.5 to 3.0 per cent fibrinogen solution containing 1.5 per cent $\mathrm{NaCl}$ and 5 per cent of the imidazole buffer solution was stored at $-20^{\circ} \mathrm{C}$. Prior to use, a test tube containing the stored fibrinogen solution was thawed in a $37.5^{\circ} \mathrm{C}$. water bath. The fibrinogen was then diluted with 0.9 per cent $\mathrm{NaCl}$ and distilled water to a fibrinogen concentration of 0.2 per cent and a final salinity equivalent to 0.9 per cent $\mathrm{NaCl}$. These fibrinogen solutions were stable for five hours or longer when maintained at $37.5^{\circ} \mathrm{C}$.

Thrombin, Topical, was employed to clot the fibrinogen. The solution, containing 2500 Iowa units per ml., was prepared by dissolving the thrombin in 0.9 per cent $\mathrm{NaCl}$ and adding 50 per cent glycerol for stabilization during storage under refrigeration.

Bovine fibrinolysin 5 was dissolved and standardized for the antifibrinolysin assay as described in previous reports $(7,8)$.

The phenol reagent of Folin and Ciocalteu (9) was used to determine tyrosine in the assay of fibrinogen.

Collection and preparation of plasma. Nine parts of human blood, obtained from the antecubital vein without stasis, was immediately mixed with one part of $\mathbf{3 . 2}$ per cent sodium citrate. The plasma was removed by pipetting, after centrifugation and reading of the hematocrit. All fibrinogen determinations were completed during the day on which the blood was drawn. The plasma was stored at $-20^{\circ} \mathrm{C}$. whenever profibrinolysin or antifibrinolysin assays could not be completed on the same day.

${ }^{8}$ Generously supplied by Dr. J. M. Ruegsegger of the Lederle Laboratories Division, the American Cyanamide Co.

- Generously supplied through the courtesy of E. C. Loomis of Parke, Davis and Co.

5 Generously supplied through the courtesy of E. C. Loomis of Parke, Davis and Co. 
Profibrinolysin isolation and assay. The separation of profibrinolysin from antifibrinolysin and other interfering substances was accomplished by treatment with protamine sulfate, alteration in $\mathrm{pH}$, dilution, centrifugation, and digestion of any remaining fibrinogen following activation of the proenzyme with streptokinase. Studies have indicated that this procedure results in the quantitative precipitation of profibrinolysin. Four $\mathrm{mg}$. of protamine sulfate were added to a $2 \mathrm{ml}$. aliquot of the plasma by pipetting in $0.5 \mathrm{ml}$. of the protamine sulfate solution. The $\mathrm{pH}$ of the mixture was brought to 9.0 (glass electrode) by adding $0.1 \mathrm{M} \mathrm{NaOH}$ dropwise with stirring. After allowing the solution to remain at $\mathrm{pH}$ 9.0 for one hour at room temperature, it was diluted with distilled or demineralized water to a volume of 40 $\mathrm{ml}$. and the $\mathrm{pH}$ adjusted to 7.0 (glass electrode) with 0.1 $\mathrm{M} \mathrm{HCl}$. With dilution and lowering the $\mathrm{pH}$ a fairly heavy precipitate, which contained fibrinogen and profibrinolysin, appeared. The precipitate was separated in $50 \mathrm{ml}$. containers by centrifugation for 30 minutes at 3000 r.p.m. (2000 RCF). The supernatant, containing antifibrinolysin, was decanted and discarded. No measurable fibrinolytic activity following treatment with streptokinase has ever been found in numerous tests of the supernatant. Traces of antifibrinolysin occasionally remained with the precipitate, but the amount present was barely detectable by the most sensitive assay methods. The trace contamination with antifibrinolysin was removed by repeated washing with distilled water and recentrifugation in several experiments but this procedure did not improve the accuracy or precision of the method.

When added to the test plasma, profibrinolysin preparations prepared by the method of Kline (10), may be recovered as fibrinolysin. However, if an appreciable quantity of profibrinolysin is added to plasma, the amount of streptokinase utilized for activation must also be increased, since the reaction between streptokinase and profibrinolysin appears to be stoichiometric (11). In the analyses reported here, additional streptokinase was added to the precipitates from a number of the native plasmas in which the fibrinolytic activity, as measured in the conventional assay, was high. No additional fibrinolysin was recovered when the higher concentrations of streptokinase were used, indicating that the streptokinase preparations in use for the assays reported here were adequate for complete activation. Furthermore, the statistical increase obtained in profibrinolysin in malignancy and pregnancy is indicative of adequate activation of the proenzyme.

No fibrinolytic activity was detectable in the precipitates. To activate the proenzyme, the precipitate was brought to a volume of approximately $2 \mathrm{ml}$. by suspending it in a solution containing $0.7 \mathrm{ml}$. imidazole buffer, $1.0 \mathrm{ml}$. of 0.9 per cent $\mathrm{NaCl}$ and $0.1 \mathrm{ml}$. of the streptokinase solution (1500 units). During an incubation period of one-half hour in the $37.5^{\circ} \mathrm{C}$. water bath the profibrinolysin was converted to fibrinolysin and the fibrinogen residues which remained in the precipitate were digested.
In determining the fibrinolytic activity, aliquots of the activated re-dissolved precipitate were diluted with saline to adjust the lysis times of 0.1 per cent fibrin clots to between 200 and 400 seconds. $^{.}$Dilutions of the fibrinolysin in the clot between 1 to 16 and 1 to 64 usually produced lysis within the prescribed time range. In making this assay, $0.2 \mathrm{ml}$. of the diluted, activated fibrinolysin solution to be tested was pipetted into a test tube, 50 $\mathrm{mm}$. $\times 8 \mathrm{~mm}$. I.D. As $0.2 \mathrm{ml}$. of 0.2 per cent fibrinogen was pipetted into the tube a stop watch was started. Thrombin was immediately added by stirring the mixture with a $2 \mathrm{~mm}$. diameter rod which had been wetted with the thrombin described above. The tube was placed in a $37.5^{\circ}$ water bath and allowed to remain there except when examined for the lytic end-point. A solid clot formed within 15 to 20 seconds after the thrombin was added. The progress of the lysis was followed by tipping the tube at intervals. Just prior to the end-point the clot acquired a semifluid consistency and slid down the tube with a humped appearance. The end-point was reached when the "hump" disappeared. Occasional debris was disregarded. Lysis times were determined in triplicate for each $2 \mathrm{ml}$. sample of plasma and in most cases duplicate samples of plasma were analyzed.

The $37.5^{\circ} \mathrm{C}$. assay curve in Figure 1 was based upon dilutions of the activated plasma profibrinolysin (procedure described above) from approximately 200 individuals. The average values for each dilution of all determinations were utilized in constructing this curve. This $37.5^{\circ}$ curve coincided with the curve obtained by dilution of bovine fibrinolysin (Loomis) with assay at $37.5^{\circ} \mathrm{C}$. and the units are the same as those which have previously been described except that the centiunit is $1 / 100$ of the conventional unit. The $28^{\circ} \mathrm{C}$. curve is included since the assay for fibrinolysin was originally described at this temperature and repeated checks have indicated that the human profibrinolysin assay also falls on this curve when the lysis is carried out at $28^{\circ} \mathrm{C}$. The identical slopes of the human profibrinolysin assay curves and the bovine fibrinolysin assay curves would indicate that there is no more inhibitor in our profibrinolysin preparations than in the best bovine fibrinolysin available.

Antifibrinolysin assay. This assay has been described in detail $(7,8)$; in essence it involves measuring the amount of residual bovine fibrinolysin, following incubation under controlled conditions of a known quantity of fibrinolysin with diluted defibrinated plasma. Arbi-

6 If the dilutions do not follow the assay curves (Figure 1) when clots lyse within the 200 to 400 seconds time range, greater dilutions of the material (longer lysis times) fall on the curve. In all of the studies reported in this paper, dilutions followed the curve when the lysis times were between 200 and 400 seconds. However, with some streptokinase preparations which have been obtained recently the dilutions did not follow the curve in the higher concentration ranges. This discrepancy appears to result from inhibitors associated with the streptokinase. 


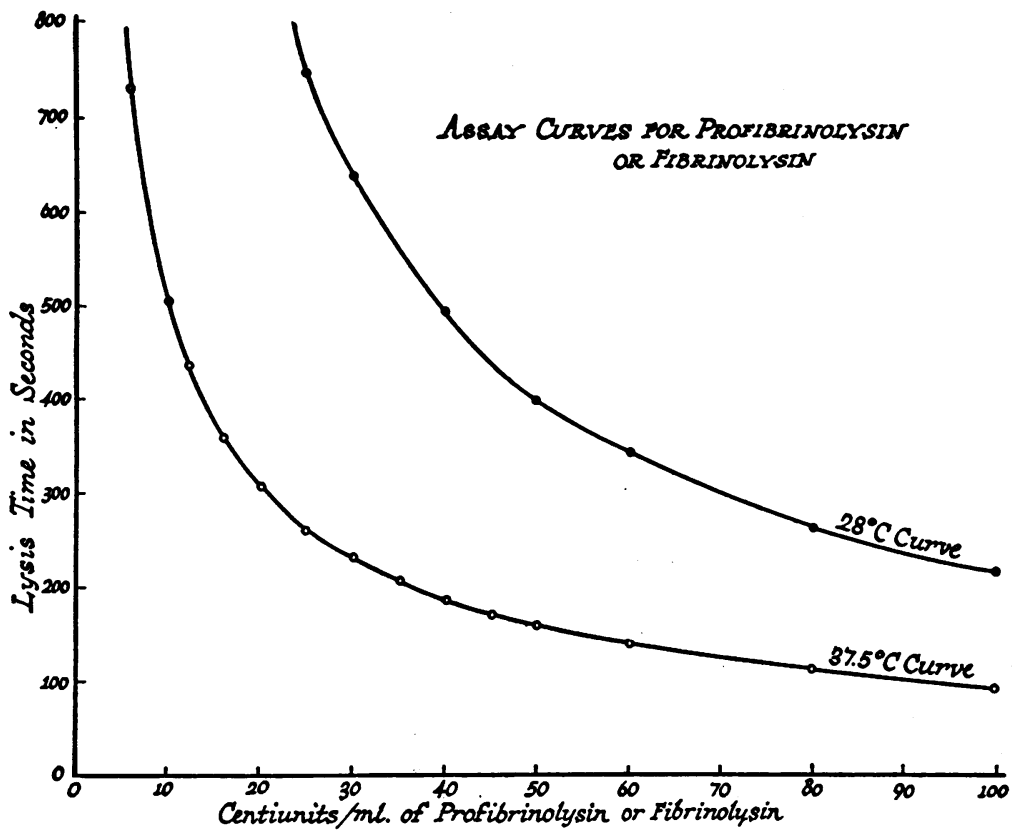

Fig. 1. Assay Curves for Human Profibrinolysin or Fibrinolysin at $28^{\circ}$ C. and $37.5^{\circ}$ C., Based upon the Average Lysis Times at Eight Dilutions of 200 Human Plasma Fibrinolysin Preparations, Each Prepared in Duplicate

These curves coincide with curves at $28^{\circ} \mathrm{C}$. and $37.5^{\circ} \mathrm{C}$. prepared by dilution of bovine fibrinolysin supplied by E. C. Loomis.

trary units of antifibrinolysin are based on the quantity of fibrinolysin inactivated.

Fibrinogen assay. The method of Ware, Guest, and Seegers (6) was employed, in which the fibrinogen in diluted plasma is clotted with thrombin; the fibrin clot is wound out on a stainless steel wire, washed with saline and hydrolyzed by $\mathrm{NaOH}$ at $100^{\circ} \mathrm{C}$. The liberated tyrosine is determined by the method of Folin and Ciocalteu (9).

Assay of urine fibrinolytic factors. In this study no attempt was made to differentiate between urine kinase, an enzyme which accelerates the conversion of profibrinolysin to fibrinolysin, and urine fibrinoprotease, an enzyme which causes direct lysis of the fibrin clot in the absence of profibrinolysin.

Assay for the fibrinolytic factors was carried out on the first morning specimen from normal individuals and all patients except pregnant women. The urine was dialyzed against running tap water until a specific resistance of over 7000 ohms was obtained. A $0.3 \mathrm{ml}$. aliquot of the dialyzed urine was placed in the same type test tube used in the profibrinolysin and antifibrinolysin assays. To this was added $0.1 \mathrm{ml}$. of 0.2 per cent fibrinogen solution and the mixture clotted by the addition of thrombin with a stirring rod. The tubes were placed in a $37.5^{\circ}$ water bath until the lysis end-point described above was obtained.

\section{RESULTS}

The maximum variation in duplicate profibrinolysin determinations on the same blood sample was \pm 10 per cent of the mean of the two values. The range in variation of profibrinolysin titers between individuals was not as great as for fibrinogen and antifibrinolysin. The lowest titer encountered was 91 centiunits in a normal individual and the highest was 260 centiunits in a patient with a breast carcinoma. However, there was a tendency toward an increase in profibrinolysin in plasmas from patients with neoplasms and in plasmas from pregnant women when compared with the mean concentration in plasmas from normal individuals. The results are graphically summarized in Figure 2 and the statistical significance of the differences is indicated in Table I.

The lowest antifibrinolysin titer was 57 units in a normal individual and the highest was 376 units in a patient with carcinoma of the breast. Pregnant women as a group, however, exhibited the highest antifibrinolysin titers of the categories 
TABLE I*

Statistical analysis

\begin{tabular}{|c|c|c|c|c|c|c|c|c|c|}
\hline & \multirow{2}{*}{$\begin{array}{l}\text { No. } \\
\text { plasma } \\
\text { samples } \\
\text { analyzed }\end{array}$} & \multicolumn{2}{|c|}{$\begin{array}{l}\text { Pro- } \\
\text { fibrinolysin }\end{array}$} & \multicolumn{2}{|c|}{$\begin{array}{l}\text { Anti- } \\
\text { fibrinolysin }\end{array}$} & \multicolumn{2}{|c|}{ Fibrinogen } & \multicolumn{2}{|c|}{ Urine lysis } \\
\hline & & $\begin{array}{l}\text { Mean } \\
\text { units }\end{array}$ & $\sigma$ & $\begin{array}{l}\text { Mean } \\
\text { units }\end{array}$ & $\sigma$ & $\underset{\text { mg. \% }}{\text { Mean }}$ & 。 & $\begin{array}{c}\text { Mean } \\
\text { times }\end{array}$ & - \\
\hline $\begin{array}{l}\text { Normal } \\
\text { All neoplasms } \\
\text { Skin tumors } \\
\text { Ca breast } \\
\text { Pregnancy }\end{array}$ & $\begin{array}{l}26 \\
74 \\
29 \\
20 \\
24\end{array}$ & $\begin{array}{l}154 \\
174 \\
180 \\
181 \\
191\end{array}$ & $\begin{array}{l}25 \\
43 \\
45 \\
50 \\
21\end{array}$ & $\begin{array}{l}110 \\
136 \\
117 \\
147 \\
207\end{array}$ & $\begin{array}{l}27 \\
47 \\
32 \\
65 \\
36\end{array}$ & $\begin{array}{l}268 \\
352 \\
351 \\
330 \\
584\end{array}$ & $\begin{array}{r}72 \\
92 \\
88 \\
57 \\
134\end{array}$ & $\begin{array}{l}37 \\
32 \\
34 \\
32 \\
-\end{array}$ & $\begin{array}{l}13 \\
12 \\
15 \\
12 \\
\end{array}$ \\
\hline \multicolumn{2}{|c|}{$\begin{array}{l}\text { All neoplasms higher than normal } \\
\text { Skin tumor higher than normal } \\
\text { Ca breast higher than normal } \\
\text { Pregnancy higher than normal }\end{array}$} & \multicolumn{2}{|c|}{$\begin{array}{l}\mathrm{P}<0.01 \\
\mathrm{P}<0.01 \\
\mathrm{P}<0.03 \\
\mathrm{P}<0.01\end{array}$} & \multicolumn{2}{|c|}{$\begin{array}{c}P<0.01 \\
\text { not significant } \\
P<0.02 \\
P<0.01\end{array}$} & \multicolumn{2}{|c|}{$\begin{array}{l}\mathrm{P}<0.01 \\
\mathrm{P}<0.01 \\
\mathrm{P}<0.01 \\
\mathrm{P}<0.01\end{array}$} & \multicolumn{2}{|c|}{$\bar{z}$} \\
\hline
\end{tabular}

* Probability, $\mathrm{P}<0.01$, means that the probability of the result being due to chance is less than 1 in 100 . The probability, $P$, was derived from the $t$ test.

studied. Although the antifibrinolysin titers tended to be higher in patients with neoplasms than in normal individuals, this alteration was too variable to be of diagnostic significance.

The tendency for an increase in concentration of a specific plasma protein in disease and in preg- nancy was of the same general magnitude for fibrinogen as for antifibrinolysin. The lowest fibrinogen concentration was $153 \mathrm{mg}$. per cent in a normal individual and the highest was $859 \mathrm{mg}$. per cent in a pregnant patient. Thus the highest fibrinogen concentration was 450 per cent greater

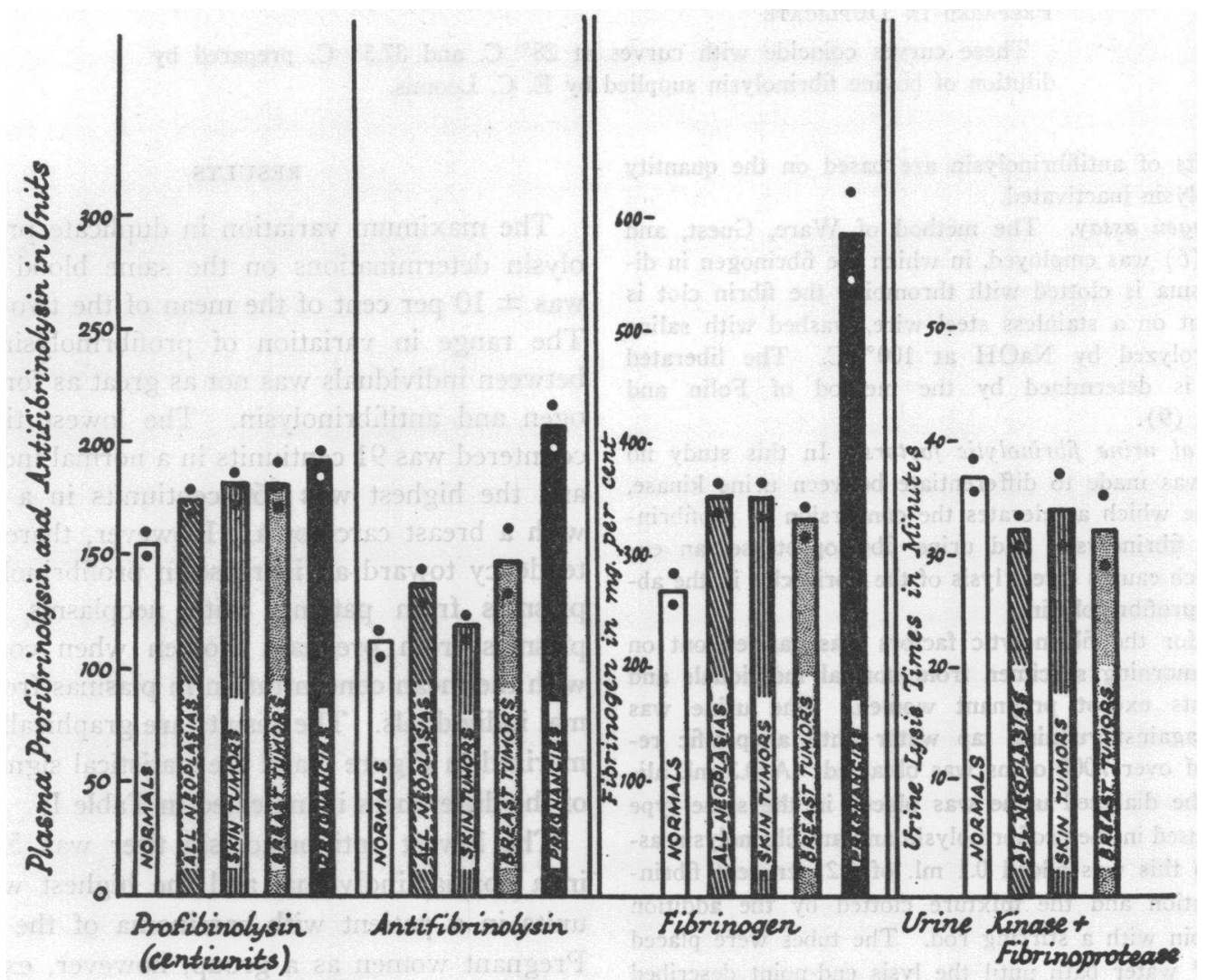

Fig. 2. Graphical Summary of Data on Normal Individuals and Hospital Patients 
than the lowest fibrinogen concentration in this series and the highest antifibrinolysin titer was 560 per cent greater than the lowest. In contrast the highest profibrinolysin titer was only 94 per cent greater than the lowest. Again, as with antifibrinolysin titers, pregnant women exhibited the highest fibrinogen concentrations of any group.

Lysis of 0.05 per cent fibrin clots by the urine dialysates from different individuals required from 12 to 75 minutes. Lysis times observed with the dialyzed urine from patients with neoplasms tended to be shorter than those found in dialyzed urine of normal individuals. However, as with the other determinations there was considerable overlap among individuals of the pathological and normal groups.

\section{DISCUSSION}

A large gap in our present knowledge of the profibrinolysin - fibrinolysin - antifibrinolysin system involves the means by which profibrinolysin is physiologically activated to fibrinolysin. Although kinases from various tissues and physiologic fluids have been described, their functional significance is unknown. Astrup and Permin (12), Permin (13), Tagnon and Petermann (14), and Lewis and Ferguson (15), have obtained factors from tissues which accelerate the conversion of profibrinolysin to fibrinolysin, and Lewis and Ferguson have reported that a fibrinokinase is present in canine serum (16). A fibrinokinase has also been found in urine (17-19). However, it has not been demonstrated that any of these factors are responsible for the modification of the profibrinolysin-fibrinolysin-antifibrinolysin system which has been reported in conditions of shock $(20)$, general stress $(21,22)$ or allergic states (5, 22).

Since the physiologic mechanism of activation of profibrinolysin is unknown and physiologic activators are not now available, it is necessary for assay of the proenzyme to use some other method of activation. Streptokinase, a bacterial product, is available in a relatively purified state; has good stability and has high potency with respect to the degree of activation achieved, but it must be recognized that streptokinase may not have the same mode of action as the physiologic activators and that the degree of activity obtained may be in part dependent upon other factors in human plasma in addition to profibrinolysin. Mullertz and Lassen have recently concluded that streptokinase converts a prokinase of human plasma to an active kinase and that the plasmatic kinase is responsible for the transformation of profibrinolysin to fibrinolysin (23). The experimental findings of Mullertz and Lassen have been confirmed in this laboratory, but their interpretation is not the only one possible. As has been suggested by Kocholaty, Ellis, and Jensen, fibrinolysin may activate profibrinolysin in a similar manner to the activation of trypsinogen by trypsin (24). Notwithstanding the uncertainty concerning the mode of action of streptokinase, it offers the best presently available material for the activation of human profibrinolysin.

In addition to the question concerning the relationship of streptokinase activatable human profibrinolysin to physiologically activatable plasma profibrinolysin, the effect of possible contamination of the material assayed with antifibrinolysin must be considered. Antifibrinolysin titers have been shown to rise in a number of disease states (25-27), including cancer $(26,28,29)$. Thus, if the isolation procedure for profibrinolysin does not free the product of this contaminant, it is logical to conclude that the fibrinolytic activity resulting from activation of the profibrinolysin is a function of at least two variables: the amount of profibrinolysin and the amount of antifibrinolysin in the native plasma. Since antifibrinolysin tends to increase in patients with malignant neoplasms, this contaminant could mask a real increase in profibrinolysin. Cliffton (27) has obtained data which he interprets as suggestive of a fall in both spontaneous and streptokinase activatable profibrinolytic activity in malignant neoplasms as compared to the other conditions tested. The inverse relationship between proteolytic and antiproteolytic titers could have resulted from the incomplete separation of antifibrinolysin, as Cliffton suggests. The method described in this report essentially removes the antifibrinolysin contaminant, thus eliminating this source of error. It is therefore believed that the results reported here more nearly approximate the true changes in profibrinolysin and that an actual statistical rise in profibrinolysin occurs in the patients with neoplasms and in pregnant women.

If proliferation of tissue were the primary fac- 
tor in the alteration of the profibrinolysin-antifibrinolysin system in a patient with a neoplasm, other situations involving rapid development of new tissue might be expected to exhibit similar changes. Pregnancy appears to have certain aspects in common with neoplasia. In pregnancy there is a rapid proliferation of new tissue which is parasitic on the host and contributes nothing to the physiologic economy of the host organism. In both neoplasia and pregnancy the host organism supplies oxygen and nutrients to the rapidly proliferating tissues and products of metabolism of the parasitic tissues must be removed. The results reported here indicate that the changes in profibrinolysin, antifibrinolysin, and fibrinogen are in the same direction in neoplasia and pregnancy, but that the changes tend to be greater in pregnancy than in neoplasia. However, it cannot be assumed from these results that the only stimulus is cell proliferation, since many other factors, such as the oxygen available to the tissues of the host organism, stress, hormones, products of metabolism and of necrosing cells, etc., may be common to the two conditions. Nevertheless, the similarities in pregnancy and neoplasia and the similarities in response of the profibrinolysin-antifibrinolysin system suggest the use of pregnant women for a comparative study, especially since the stage of pregnancy can be readily determined and the patient can be made available for post partum control studies.

The lysis of fibrin clots, or hydrolysis of other proteins, in the presence of urine dialysates or concentrates at $\mathrm{pH} 7.2$ to 7.4 has been reported from several laboratories. Williams (17) and Astrup and Sterndorff (18) have claimed that the breakdown of the fibrin clot is due almost entirely to the activation of a profibrinolysin contaminant in the fibrin substrate by a urine fibrinokinase. Recently in this laboratory evidence has been obtained that human urine and urine from other species have, in addition to fibrinokinase activity, a fibrinoprotease activity (19). This fibrinoprotease activity brings about the direct lysis of fibrin clots in the absence of profibrinolysin. It is emphasized, however, that the results reported here do not distinguish between kinase and protease, since bovine fibrinogen, prepared by the freezethawing technic, may occasionally be contaminated with traces of profibrinolysin. The assay reported here, therefore, only indicates total lytic potency of the urine samples. In some cases the lysis could have been largely due to activation of the profibrinolysin contaminant by urine kinase; in others, the lysis could have been the result of the direct lysis of bovine fibrin by urine fibrinoprotease, or both urine kinase and fibrinoprotease could contribute to the fibrinolytic end-point.

\section{SUMMARY}

1. An assay for human plasma profibrinolysin is described in which the profibrinolysin is isolated through treatment with protamine sulfate, dilution and $\mathrm{pH}$ alteration. After activation with streptokinase the fibrinolytic activity is measured by the rate of lysis of a standard fibrin clot.

2. A method for measuring urine fibrinolytic activity is described. Salts are removed by dialysis and fibrinolytic activity is measured by the rate of lysis of a fibrin clot.

3. Plasma profibrinolysin, antifibrinolysin, and fibrinogen concentrations are increased in patients with neoplasms and in pregnant women when compared to the mean concentrations of these factors in normal individuals.

4. Plasma profibrinolysin, antifibrinolysin, and fibrinogen tend to show greater increases in pregnant women than in patients with neoplasia.

\section{REFERENCES}

1. Milstone, H., A factor in normal human blood which participates in streptococcal fibrinolysis. J. Immunol., 1941, 42, 109.

2. Ratnoff, O. D., Studies on a proteolytic enzyme in human plasma. III. Some factors controlling the rate of fibrinolysis. J. Exper. Med., 1948, 88, 401.

3. Downie, G. R., and Cliffton, E. E., A method for assay of serum proteolytic activity. Proc. Soc. Exper. Biol. \& Med., 1949, 71, 138.

4. Christensen, L. R., and Smith, D. H., Jr., Plasminogen purification by acid extraction. Proc. Soc. Exper. Biol. \& Med., 1950, 74, 840.

5. Burdon, K. L., Guthrie, R. K., and Rick, DeL. F., Role of activated blood protease in anaphylactic and anaphylactoid reactions. Federation Proc., 1951, 10, 404.

6. Ware, A. G., Guest, M. M., and Seegers, W. H., Fibrinogen: With special reference to its preparation and certain properties of the product. Arch. Biochem., 1947, 13, 231.

7. Guest, M. M., Ware, A. G., and Seegers, W. H., A quantitative study of antifibrinolysin in chick plasma: increase in antifibrinolysin activity during pteroylglutamic acid deficiency. Am. J. Physiol., 1947, 150, 661. 
8. Guest, M. M., Daly, B. M., Ware, A. G., and Seegers, W. H., A study of antifibrinolysin activity in the plasmas of various animal species. J. Clin. Invest., 1948, $27,785$.

9. Folin, O., and Ciocalteu, V., On tyrosine and tryptophane determinations in proteins. J. Biol. Chem., 1927, 73, 627.

10. Kline, D. L., The purification and crystallization of plasminogen (profibrinolysin). J. Biol. Chem., 1953, 204, 949.

11. Wasserman, A. E., Streptokinase activation of a proteolytic enzyme in human blood. Arch. Biochem. Biophys., 1952, 41, 158.

12. Astrup, T., and Permin, P. M., Fibrinolysis in the animal organism. Nature, 1947, 159, 681.

13. Permin, P. M., Properties of the fibrinokinasefibrinolysin system. Nature, 1947, 160, 571.

14. Tagnon, H. J., and Petermann, M. L., Activation of proplasmin by a tissue fraction. Proc. Soc. Exper. Biol. \& Med., 1949, 70, 359.

15. Lewis, J. H., and Ferguson, J. H., Studies on a proteolytic enzyme system of the blood. II. Fibrinolysokinase activators for profibrinolysin. J. Clin. Invest., 1950, 29, 1059.

16. Lewis, J. H., and Ferguson, J. H., Studies on a proteolytic enzyme system of the blood. IV. Activation of profibrinolysin by serum fibrinolysokinase. Proc. Soc. Exper. Biol. \& Med., 1951, 78, 184.

17. Williams, J. R. B., The fibrinolytic activity of urine. Brit. J. Exper. Path., 1951, 32, 530.

18. Astrup, T., and Sterndorff, I., An activator of plasminogen in normal urine. Proc. Soc. Exper. Biol. \& Med., 1952, 81, 675.

19. Guest, M. M., Mohler, S. R., and Celander, D. R., Studies on urokinase: an activator of plasma profibrinolysin extracted from urine. XIX Internat. Physiol. Congress, Montreal, Canada, Abstracts of Publications, 1953, 422.
20. Tagnon, H. J., Levenson, S. M., Davidson, C. S., and Taylor, F. H. L.; The occurrence of fibrinolysis in shock, with observations on the prothrombin time and the plasma fibrinogen during hemorrhagic shock. Am. J. M. Sc., 1946, n.s., 211, 88.

21. Macfarlane, R. G., The fibrinolytic enzyme of human blood. XVII Internat. Physiol. Cong., Oxford, July, 1947.

22. Ungar, G., Damgaard, E., and Hummel, F. P., The fibrinolysin-antifibrinolysin system in serum: mechanism of its endocrine control. Endocrinology, 1951, 49, 805.

23. Mullertz, S., and Lassen, M., An activator system in blood indispensable for formation of plasmin by streptokinase. Proc. Soc. Exper. Biol. \& Med., 1953, 82, 264.

24. Kocholaty, W., Ellis, W. W., and Jensen, H., Activation of plasminogen by trypsin and plasmin. Blood, 1952, 7, 882.

25. Guest, M. M., Daly, B. M., Ware, A. G., and Seegers, W. H., A study of the antifibrinolysin activity in human plasmas during pathological states. J. Clin. Invest., 1948, 27, 793.

26. Dillard, G. H. L., and Chanutin, A., The protease and antiprotease of plasmas of patients with cancer and other diseases. Cancer Research, 1949, 9, 665.

27. Cliffton, E. E., Variations in the proteolytic and the antiproteolytic reactions of serum: effect of disease, trauma, X-ray, anaphylactic shock, ACTH and cortisone. J. Lab. \& Clin. Med., 1952, 39, 105.

28. Clark, D. G. C., Cliffton, E. E., and Newton, B. L., Antiproteolytic activity of human serum with particular reference to its changes in the presence and consideration of its use for detection of malignant neoplasia. Proc. Soc. Exper. Biol. \& Med., 1948, 69, 276.

29. Cliffton, E. E., An evaluation of the antiproteolytic reaction of serum as a test for malignant neoplasia. J. Nat. Cancer Inst., 1950, 11, 33. 